\title{
Developing a public policy analytical operational model based on stakeholder identification and salience typology
}

\author{
Chang-Hsi $\mathrm{Yu}^{1 *}$, Chi-Kuang Chen $^{2}$, Shen-Hung Tasi ${ }^{1}$ and Hsiu-Chen Chang ${ }^{3}$ \\ ${ }^{1}$ Department of Business Administration, Yu Da University, Taiwan, Republic of China. \\ ${ }^{2}$ Department of Industrial Engineering and Management, Yuan Ze University, Taiwan, Republic of China. \\ ${ }^{3}$ Department of Accounting and Information Technology, Yu Da University, Taiwan, Republic of China.
}

Accepted 28 June, 2011

\begin{abstract}
The objective of this study is to develop an operational model for analysing public policy based on the typology of stakeholders. This typology, which categorised stakeholders into seven types on the basis of three stakeholder attributes (power, legitimacy and urgency), provided a useful conceptual definition and categorisation of stakeholders, but it failed to provide a practical framework for subsequent development of public policy, especially in the context of conflicts between various types of stakeholders. The present study therefore utilised the conceptual typology to develop a practical analytical operational model for the development of public policy in the context of potential stakeholder conflict. The operational model involved two stages and two layers in developing a procedure for analysing stakeholder conflict. A five-level evaluation system was developed to specify the level of intensity of stakeholder conflict. To demonstrate how the proposed model works, the paper presented an empirical case study of the construction of Taiwan's No. 5 National Highway.
\end{abstract}

Key words: Public policy, public management, stakeholder theory.

\section{INTRODUCTION}

The term 'stakeholder' has assumed a prominent place in management theory and practice in the past twenty years. In general, the term refers to the various influential persons, groups, or organisations that must be taken into account by the managers and staff of any organisation (Bryson, 2004). Attention to such stakeholders is important for the survival and success of organisations (Bryson, 1995; Moore, 1995). If key stakeholders are not satisfied with the performance of the organisation in terms of a range of criteria (including efficiency, effectiveness, quality of services, achieve-ment of organisational goals and so on), it is likely that something will change for example, budgets will be cut, people will lose their jobs, new initiatives will be undermined, and so on (Bryson, 2004; Chen et al., 2006; Jones et al., 2007). Indeed,

*Corresponding author. E-mail: tony@ydu.edu.tw. according to Wang et al. (2010), the wide range of criteria involved in stakeholder satisfaction implies that an organisation must embrace the principles and practices of total quality management (TQM) to establish a culture of continuous organisational improvement. Since the publication of Freeman's (1984) book entitled Strategic Management: A Stakeholder Approach, the concept of 'stakeholder management' has had a significant influence in broadening management's vision beyond profit maximisation to include the interests of persons other than financial stockholders (Mitchell et al., 1997). Stakeholder theory is now acknowledged to be a useful and appropriate perspective that can help managers to understand the turbulence of internal and external strategic environments with more confidence (Gomes et al., 2010). However, despite the growing interest in such 'stakeholder management', most studies of the subject have been restricted to private enterprise (Bryson, 2004); indeed, until relatively recently the influence of 
stakeholders on public-sector organisations has been largely ignored (Ferlie et al., 2003). The large number and variety of stakeholders involved in public-sector organisations compared with those in the private sector presents difficulties (McAdam et al., 2005), and simply translating the theory and practice of the private sector to the public sector (albeit with minor modifications) is unlikely to be sufficient because the interests and needs of stakeholders in public-sector organisations are quite different from those in the private sector (Bendheim and Graves, 1998).

Nevertheless, the application of stakeholder theory to the public sector is an important issue. As Rainey (1997) has argued: Public agencies are born of and live by satisfying interests that are sufficiently influential to maintain the agencies' political legitimacy and the resources that come with it. As a consequence, a failure by a public-sector organisation to attend carefully to stakeholder interests and information can easily lead to disaster for the organisation (Nutt, 2002; Bryson, 2004).

According to Rowley (1997), the development of stakeholder theory has focused on two related streams: (i) defining the stakeholder concept; and (ii) classifying stakeholders into categories. With regard to the second of these, McAdam et al. (2005) have contended that there is still a paucity of research on the systematic identification and analysis of stakeholders and the management of the complex and often competing relationships among them. Similarly, Hillman and Keim (2001) have argued that the “... processes by which stakeholder relations are managed and the balancing of diverse demands of stakeholder groups are ripe areas for further inquiry". In this regard, Bryson (2004) has pointed out that there is relatively little in the literature on the systematic identification and analysis of stakeholders in public-sector and non-profit organisations. The present study addresses these issues by developing a public policy analytical model based on the typology of stakeholder identification and salience proposed by Mitchell et al. (1997). Although this typology provides a useful conceptual definition and classification of stakeholders, it offers no operational analytical procedure for the subsequent development of public policy. The model proposed in this paper involves a two-stage and twolayered analytical procedure that clarifies the degree of conflict that can arise among multiple stakeholders in public policy. An empirical case study is then presented to demonstrate the procedures of the proposed analytical model.

\section{LITERATURE REVIEW AND CONCEPTUAL MODEL}

\section{Definition and categorisation of stakeholders}

In its widest sense, the term 'stakeholder' refers to persons, groups, neighbourhoods, organisations, institutions, societies and even the natural environment of an organisation (Mitchell et al., 1997). According to Freeman (1984), a stakeholder can be defined as: "any group or individual who can affect or is affected by the achievement of the organization's objectives". Thompson et al. (1991) described stakeholders in general terms as any group that is "in relationship with an organization", Hill and Jones (1992) spoke of stakeholders as contractors or participants in exchange relationships. Mitchell et al. (1997) proposed a typology of seven types of stakeholders and their salience (or importance) to an organisation. The typology, which is illustrated in Figure 1, was based on three stakeholder attributes power, legitimacy and urgency. As shown in Figure 1, among the seven types of stakeholders, three types ('dormant', 'discretionary', and 'demanding') possessed only one of the three attributes; these were characterised as 'latent stakeholders'. Another three types ('dominant', 'dangerous' and 'dependent') possessed two of the three attributes; these were characterised as 'expectant stakeholders'. Only one type of stakeholder ('definitive') possessed all three of the attributes. Individuals or entities possessing none of the attributes were classed as 'nonstakeholders' or 'potential stakeholders'. Although the typology proposed by Mitchell et al. (1997) offers a means of identifying stakeholders and an indication of their relative salience, the typology remains purely conceptual in nature. An analytical operational model is required for practical use. This study therefore attempts to develop an analytical model for public policy based on the conceptual framework of Mitchell et al. (1997).

\section{Models of stakeholder management}

\section{Functions of stakeholder theory}

According to Donaldson and Preston (1995), the three functions of stakeholder theory are: (i) descriptive/empirical; (ii) instrumental; and (iii) normative. The first of these (descriptive/empirical theory) describes and explains specific-corporate characteristics and behaviours; for example, stakeholder theory has been used to describe the nature of the firm (Brenner and Cochran, 1991) and the way in which managers think about managing (Brenner and Molander, 1977). The second (instrumental theory) identifies the connections between stakeholder management and the achievement of corporate objectives (such as profitability and growth). Finally, the third (normative theory) interprets the function of the corporation including the identification of moral or philosophical guidelines for the operation and management of the organisation.

\section{Influence of stakeholders on organisations}

An important approach to understanding the role of 


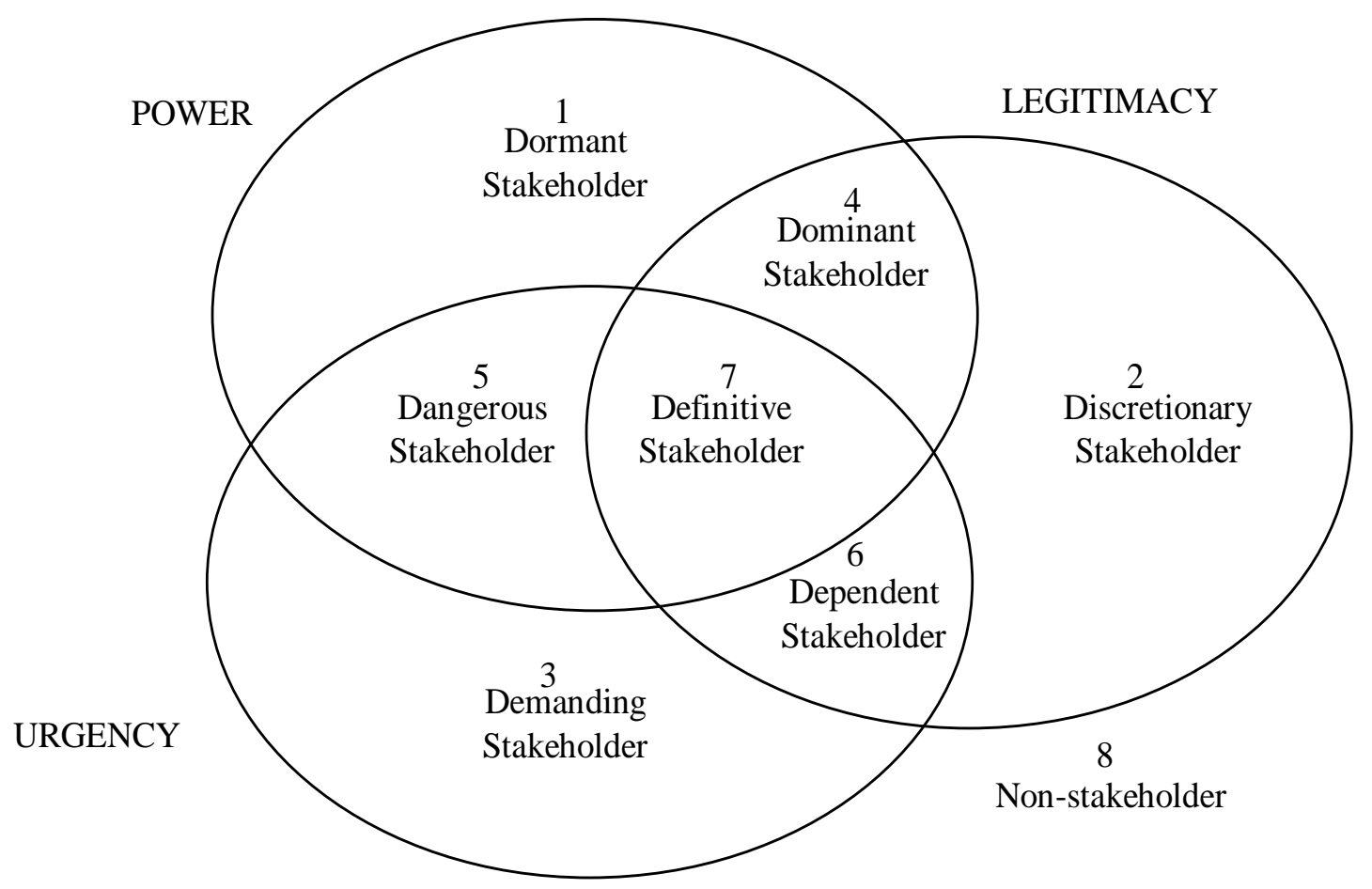

Figure 1. Stakeholder typology, Source: Mitchell and Wood (1997).

stakeholders in influencing organisations is the social network model, which employs the concept of social networks to study the structural characteristics of an organisation's network of relationships (Rowley, 1997). The theory's logic is derived from Oliver's (1991) theory of organisational responses to external influences in addressing the question of how the structure of an organisation's stakeholder relationships affects its response to stakeholder pressures. The social network model provides a conception of organisational responses to the simultaneous influence of multiple stakeholders (Rowley, 1997).

\section{Effects of stakeholder management}

The cause-and-effect model examines the relationship between stakeholder management and the financial performance or competitive advantage of a firm. According to the model, effective stakeholder management of relationships with customers, employees, suppliers, members of the public and the environment provides additional resources to enhance a firm's ability to outperform competitors in terms of long-term value creation (Hillman and Keim, 2001). Kaplan and Norton (1996) contended that the primary drivers of financial performance are the external relationships that a company develops with its customers and the internal relationships with its employees both of which shape customer relations and determine customer service.
Legnick-Hall (1996) also emphasised the importance of loyalty-producing relationships with customers that extend beyond traditional firm boundaries as a source of competitive advantage. Liao et al. (2009) indicated that perceived stakeholder importance is not sufficient; rather, the emphasis should be on a real commitment to corporate responsibility if the organisation is to reap tangible benefits.

\section{PROPOSED MODEL}

\section{Overall structure of proposed model}

Drawing on the literature review, the present study utilises the theory of stakeholder identification and salience proposed by Mitchell et al. (1997), together with the models of stakeholder management outlined above, to develop a public policy analytical model. As shown in Figure 2, this model consists of two stages and two layers. The two stages refer to: (i) assessment of stakeholder attributes (stage 1); and (ii) assessment of stakeholder salience (or importance) (stage 2). In the first stage, the stakeholders' attitudes (support, neutrality, or opposition) and issues of concern with regard to public policy are analysed in terms of the stakeholders' attributes (power, legitimacy, or urgency). In the second stage, their attitudes and issues of concern are analysed in terms of stakeholder salience ('latent', 'expectant', or 'definitive' stakeholders) (Mitchell et al., 1997). Stages 1 


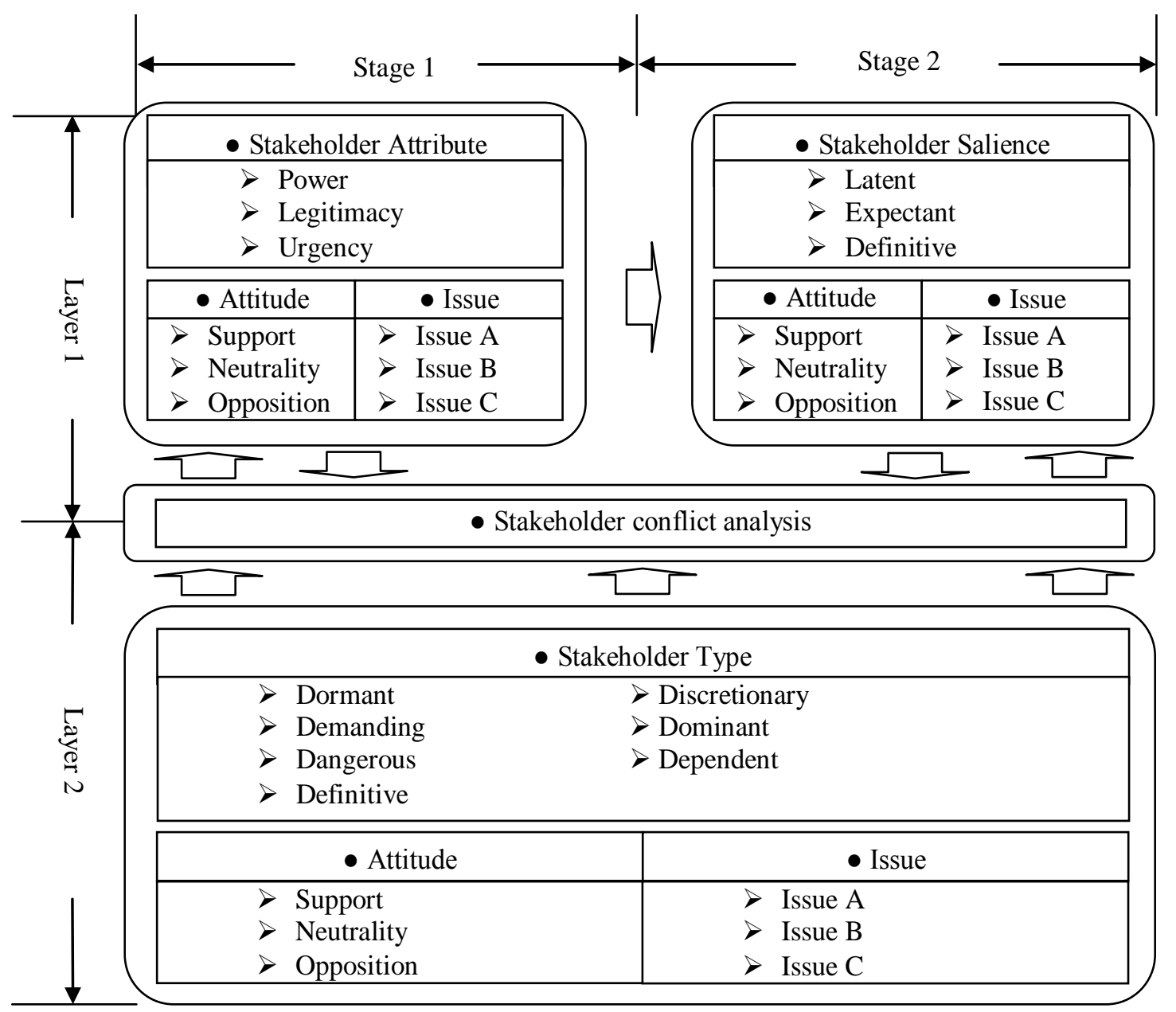

Figure 2. Proposed public policy analytical model.

and 2 form the primary layer of the model. Beneath this layer, the second layer of the model consists of an analysis of conflict points among the seven types of stakeholders ('dormant', 'demanding', 'dangerous', definitive', 'discretionary', 'dominant', 'dependent'). The major elements of Figure 2 are subsequently described in greater detail.

\section{Major elements of the proposed model}

\section{Stakeholder attributes}

As previously noted, Mitchell et al. (1997) proposed three critical stakeholder attributes: (i) power; (ii) legitimacy and (iii) urgency. According to Weber (1947), power is "the probability that one actor within a social relationship would be in a position to carry out his own will despite resistance". Stakeholder power is usually associated with resources that: (i) are concentrated or tightly controlled; (ii) are essential to operational performance; and/or (iii) having no viable substitutes. Faced with such stakeholder power, self-interested firms will usually be responsive (Jones et al., 2007). If a powerful actor also possesses legitimacy, the combination represents a legitimate use of power (Weber, 1947). However, even if an entity has a legitimate claim on an organisation and the power to enforce its will, unless there is a perception that its claim is urgent which can be defined as the degree to which stakeholder claims call for immediate attention it will not achieve salience for the organisation's managers (Mitchell et al., 1997). According to Mitchell et al. (1997), urgency is based on two characteristics: (i) time sensitivity (the degree to which managerial delay in attending to the claim is unacceptable to the stakeholder); and (ii) criticality (the importance of the claim or the relationship to the stakeholder).

\section{Stakeholder salience}

Mitchell et al. (1997) posited that a stakeholder who possesses more attributes has a higher level of salience. 
Based on the number of stakeholder attributes that a stakeholder possesses, stakeholders can be categorised as: (i) 'latent stakeholders'; (ii) 'expectant stakeholders'; or (iii) 'definitive stakeholders'. The salience of latent stakeholders is low because they possess only one of the stakeholder attributes. Such latent stakeholders include 'dormant stakeholders', 'discretionary stakeholders', and 'demanding stakeholders'. They do not have an immediate influence on an organisation. Expectant stakeholders possess moderate salience because they possess two of the stakeholder attributes. Such expectant stakeholders include 'dominant stakeholders', 'dependent stakeholders' and 'dangerous stakeholders'. Organisations must pay careful attention to expectant stakeholders because they can become definitive stakeholders if they acquire one more stakeholder attribute. The salience of definitive stakeholders is high because they possess all three of the stakeholder attributes. The satisfaction of the needs of definitive stakeholders must be considered a priority for organisations.

\section{Stakeholder type}

Seven types of stakeholders emerge from the various combinations of the three stakeholder attributes (power, legitimacy and urgency). According to Mitchell et al. (1997), the seven stakeholder types are as follows:

1. Dormant: Dormant stakeholders possess the attribute of power to impose their will on a firm; however, because they do not have a legitimate relationship or an urgent claim, their power remains unused.

2. Discretionary: Discretionary stakeholders possess the attribute of legitimacy; however, they have no power to influence the firm and have no urgent claims.

3. Demanding: Demanding stakeholders have urgent claims but possess neither the power nor the legitimacy to be significant. Although such stakeholders are irksome, they are not dangerous. As a consequence, they do not warrant more than passing management attention.

4. Dominant: Because dominant stakeholders are both powerful and legitimate, their influence on the firm is assured. The combination of power and legitimacy enables these stakeholders to form the "dominant coalition" in the enterprise (Cyert and March, 1963).

5. Dangerous: A stakeholder with urgency and power, but no legitimacy, is classed as 'dangerous' because such a stakeholder might be coercive (and possibly violent) in its dealings with the firm.

6. Dependent: Stakeholders who lack power but have urgent legitimate claims are described as 'dependent' because these stakeholders depend upon others (other stakeholders or the firm's managers) for the power to carry out their will.

7. Definitive: Stakeholder salience will be highest if a stakeholder possesses all three stakeholders' attributes power, legitimacy and urgency.

\section{Stakeholder attitude}

Stakeholder attitude refers to stakeholders' opinions on the public policy. Stakeholder attitude can be divided into: (i) support (approving or positive attitude); (ii) neutrality (neither clear approval nor opposition); and (iii) opposition (a disapproving or negative attitude towards a public policy).

\section{Issues of concern to stakeholders}

The public policy analytical model determines the issues of concern to stakeholders by conducting a content analysis of relevant information collected from stakeholders or other relevant sources. The nature and number of the issues of concern for different public policies will vary. For example, in determining a national defence policy, issues such as 'budget planning' or 'armament replacement' might be the issues of concern to the stakeholders. To take another example, policies regarding public traffic management might involve such issues as 'economic development' and 'environmental protection' for further analysis.

\section{Stakeholder conflict analysis}

The conflicting demands of multiple stakeholders with respect to a public policy are analysed quantitatively in terms of the dimensions of stakeholder attribute, stakeholder salience and stakeholder type. A 'conflict point' is said to occur when the majority of the stakeholders do not share a common attitude or a common issue of concern with respect to a given policy. For example, if a public policy has three stakeholders and all three of them share a consistent attitude towards the policy (that is, they all support, hold a neutral position, or oppose the policy), there is no conflict among the attitudes of the stakeholders. However, if only one of the three stakeholders is concerned about issue $A$, whereas the other two are both only concerned about issue $B$ or issue $\mathrm{C}$, there is an inconsistency among the issues of concern to the stakeholders, thus producing a point of conflict.

\section{RESEARCH DESIGN}

\section{Research case}

To demonstrate the application of the proposed model, a policy analysis was conducted on the construction of Taiwan's No. 5 National Highway. The construction of the highway along the east coast of Taiwan is one of the country's most significant national construction projects. Because the project has significant 
Table 1. Distribution of newspaper articles on project.

\begin{tabular}{lccccc}
\hline Analyses & United Daily News & China Times & Liberty Times & Apple Daily & Total \\
\hline Number of articles & 176 & 87 & 78 & 21 & 362 \\
Proportion of total (\%) & 48.62 & 24.03 & 21.55 & 5.8 & 100 \\
\hline
\end{tabular}

Table 2. Reliability tests of content analysis.

\begin{tabular}{lccc}
\hline Reliability analyses & Stakeholder type & Issues of concern & Stakeholder attitude \\
\hline Mutual agreement with coder A & 0.889 & 0.839 & 0.851 \\
Mutual agreement with coder B & 0.873 & 0.857 & 0.821 \\
Reliability index & 0.937 & 0.918 & 0.911 \\
\hline
\end{tabular}

implications for the region's economy, tourism, transportation and environment, it is an appropriate case for stakeholder analysis.

\section{Data collection}

To achieve the research objective stated above, the secondary data analysis approach is chosen. The reason for using this research approach is that in an exploratory type of empirical study, the secondary data analysis is one of the preferred strategies. In addition, the secondary data analysis can provide more deep information and clear idea for exploratory studies (Cooper and Schindler, 2008). Newspaper reports on the interactions among stakeholders regarding the construction of the highway provided research data for the empirical study. The choice of newspapers as the basis for data collection was in accordance with the view of Becker (1979), who contended that newspaper reports provided better public information than television reports because the former were usually of greater depth than the latter. The four domestic newspapers with the highest readerships in Taiwan-the United Daily News (19.75\%), Liberty Times (17.23\%), Chinese Times (17.10\%) and Apple Daily (15.70\%), were used for data-collection purposes (Rainmaker XKM, 2006). The news database of the Taiwanese National Library was searched for reports in these four newspapers related to the construction of No. 5 National Highway.

\section{Issues of concern}

After reviewing the newspaper reports on all the stakeholders of the No. 5 National Highway construction plan, the present study identified four issues of concern regarding this project: (i) transportation development and planning (ii) environmental protection (iii) economic development (including tourism plans and competitiveness) and (iv) decision-making processes (including changes in policy, political resistance and negotiations between central and local governments).

\section{Stakeholders' attitudes}

Stakeholders' attitudes were placed into three categories on the basis of the news reports: (i) support for the construction of the No. 5 National Highway; (ii) opposition to the construction; and (iii) neutrality (neither apparent support nor opposition).

\section{Stakeholder types}

After reviewing the newspaper reports on all the stakeholders of the
No. 5 National Highway construction plan, seven types of stakeholders were identified: (i) definitive stakeholders (such as central government agencies and directors of the central ministries); (ii) dangerous stakeholders (such as environmental protection activist groups); (iii) dependent stakeholders (such as local tourism associations and syndicates); (iv) dominant stakeholders (such as local government agencies); (v) dormant stakeholders (such as scholars); (vi) discretionary stakeholders (such as local citizens); and (vii) demanding stakeholders (such as the construction contractors).

\section{RESULTS}

\section{Data description}

As shown in Table 1, the study collected 362 news articles dated between 2003 and 2007. Of these 362 articles, $176(48.62 \%)$ were from the United Daily, 87 (24.03\%) were from the China Times, $78(21.55 \%)$ were from the Liberty Times, and 21 (5.8\%) were from Apple Daily.

\section{Reliability tests of content analysis}

Reliability tests of content analysis were conducted on the data by the principal researcher and two additional coders. Comparisons of content analyses were conducted with regard to: (i) stakeholder type; (ii) issues of concern; and (iii) stakeholder attitude. Reliability indices were established by the following formula:

Reliabilit $y=\frac{2 \times \text { Degree of average mutual agreement }}{1+[(2-1) \times \text { Degree of average mutual agreement }]}$

Indices of mutual agreement were determined in accordance with the following formula:

Degree of mutual agreement $=\frac{2 \times \text { number of items completely agreed by twoparties }}{\text { number agreed by Party A }+ \text { number agreed by Party B }}$

The results are shown in Table 2. It is apparent that there was a high degree of agreement between the researcher and the two coders, which indicates that results of 
Table 3. Attitudes of stakeholders with different attributes.

\begin{tabular}{lcccc}
\hline Attribute & Neutrality (\%) & Opposition (\%) & Support (\%) & Total (\%) \\
\hline Legitimacy & $134(50.2)$ & $17(6.4)$ & $116(43.4)$ & $267(100)$ \\
Urgency & $139(51.9)$ & $48(17.9)$ & $81(30.2)$ & $268(100)$ \\
Power & $162(47.8)$ & $72(21.2)$ & $105(31)$ & $339(100)$ \\
Total & $435(49.8)$ & $137(15.7)$ & $302(34.5)$ & $874(100)$ \\
\hline
\end{tabular}

Table 4. Issues of concern for stakeholders with different attributes.

\begin{tabular}{lccccc}
\hline Attribute & $\begin{array}{c}\text { Environmental } \\
\text { protection (\%) }\end{array}$ & $\begin{array}{c}\text { Transportation } \\
\text { development (\%) }\end{array}$ & $\begin{array}{c}\text { Decision-making } \\
\text { process (\%) }\end{array}$ & $\begin{array}{c}\text { Economic } \\
\text { development (\%) }\end{array}$ & Total (\%) \\
\hline Legitimacy & $59(19.5)$ & $71(23.5)$ & $140(46.4)$ & $32(10.6)$ & $302(100)$ \\
Urgency & $93(31.5)$ & $56(19)$ & $117(39.7)$ & $29(9.8)$ & $295(100)$ \\
Power & $122(32.5)$ & $67(17.9)$ & $149(39.7)$ & $37(9.9)$ & $375(100)$ \\
Total & $274(28.2)$ & $194(20)$ & $406(41.8)$ & $98(10)$ & $972(100)$ \\
\hline
\end{tabular}

Table 5. Stakeholders' salience and attitude.

\begin{tabular}{lcccc}
\hline Stakeholders' salience & Neutrality (\%) & Opposition (\%) & Support (\%) & Total (\%) \\
\hline Latent stakeholders & $15(31.3)$ & $30(62.5)$ & $3(6.2)$ & $48(100)$ \\
Expectant stakeholders & $36(31)$ & $37(31.9)$ & $43(37.1)$ & $116(100)$ \\
Definitive stakeholders & $116(58.6)$ & $11(5.5)$ & $71(35.9)$ & $198(100)$ \\
Total & $167(46.1)$ & $78(21.6)$ & $117(32.3)$ & $362(100)$ \\
\hline
\end{tabular}

Table 6. Stakeholders' salience and issues of concern.

\begin{tabular}{lccccc}
\hline Stakeholders' salience & $\begin{array}{c}\text { Environmental } \\
\text { protection (\%) }\end{array}$ & $\begin{array}{c}\text { Transportation } \\
\text { development (\%) }\end{array}$ & $\begin{array}{c}\text { Decision-making } \\
\text { process (\%) }\end{array}$ & $\begin{array}{c}\text { Economic } \\
\text { development (\%) }\end{array}$ & Total (\%) \\
\hline Latent stakeholders & $29(52.7)$ & $4(7.3)$ & $13(23.6)$ & $9(16.4)$ & $55(100)$ \\
Expectant stakeholders & $46(34.6)$ & $23(17.3)$ & $39(29.3)$ & $25(18.8)$ & $133(100)$ \\
Definitive stakeholders & $51(23.5)$ & $48(22.1)$ & $105(48.4)$ & $13(6)$ & $217(100)$ \\
Total & $126(31.1)$ & $75(18.5)$ & $157(38.8)$ & $47(11.6)$ & $405(100)$ \\
\hline
\end{tabular}

content analysis in the study were reliable.

\section{Stakeholder attribute analyses}

As shown in Table 3, no significant differences were identified in the analysis of the attributes and attitudes of stakeholders. Similar proportions of neutrality, opposition and support were found among stakeholders with different attributes (legitimacy, urgency and power). As shown in Table 4, no significant differences were identified in the issues of concern for stakeholders with different attributes Stakeholders with different attributes all gave priority to the decision-making process. In summary, there were no significant differences in either the attitudes or issues of concern among stakeholders with different attributes.

\section{Stakeholder salience analyses}

Table 5 shows that stakeholders of different salience had different attitudes towards the highway construction project. Most of the latent stakeholders were opposed to the project, whereas most of the definitive stakeholders held a neutral attitude. The expectant stakeholders were, in general, evenly distributed in their attitudes. Table 6 shows that stakeholders of different salience were concerned about different issues. Latent stakeholders and expectant stakeholders were more concerned about environmental issues than other issues. In contrast, the largest proportion of the definitive stakeholders was concerned about the decision-making process. Latent and expectant stakeholders were somewhat concerned about the issue of economic development, but definitive stakeholders had little concern for this issue. 
Table 7. Attitudes of stakeholder types with power attribute.

\begin{tabular}{lcccc}
\hline Types of stakeholder & Neutrality (\%) & Opposition (\%) & Support (\%) & Total (\%) \\
\hline Dominant stakeholders & $15(30.6)$ & $0(0)$ & $34(69.4)$ & $49(100)$ \\
Dangerous stakeholders & $21(38.9)$ & $33(61.1)$ & $0(0)$ & $54(100)$ \\
Definitive stakeholders & $116(58.6)$ & $11(5.5)$ & $71(35.9)$ & $198(100)$ \\
Dormant stakeholders & $10(26.3)$ & $28(73.7)$ & $0(0)$ & $38(100)$ \\
Total & $162(47.8)$ & $72(21.2)$ & $105(31)$ & $339(100)$ \\
\hline
\end{tabular}

Table 8. Issues of concern for stakeholder types with power attribute.

\begin{tabular}{lccccc}
\hline Types of stakeholder & $\begin{array}{c}\text { Environmental } \\
\text { protection (\%) }\end{array}$ & $\begin{array}{c}\text { Transportation } \\
\text { development (\%) }\end{array}$ & $\begin{array}{c}\text { Decision-making } \\
\text { process (\%) }\end{array}$ & $\begin{array}{c}\text { Economic } \\
\text { development (\%) }\end{array}$ & Total (\%) \\
\hline Dominant stakeholders & $4(6)$ & $15(26.8)$ & $30(51.7)$ & $9(15.5)$ & $58(100)$ \\
Dangerous stakeholders & $41(70.7)$ & $2(3.4)$ & $7(12.1)$ & $8(13.8)$ & $58(100)$ \\
Definitive stakeholders & $51(23.5)$ & $48(22.1)$ & $105(48.4)$ & $13(6)$ & $217(100)$ \\
Dormant stakeholders & $26(61.9)$ & $2(4.7)$ & $7(16.7)$ & $7(16.7)$ & $42(100)$ \\
Total & $122(32.5)$ & $67(17.8)$ & $149(39.7)$ & $37(10)$ & $375(100)$ \\
\hline
\end{tabular}

Table 9. Attitudes of stakeholder types with legitimacy attribute.

\begin{tabular}{lcccc}
\hline Types of stakeholder & Neutrality (\%) & Opposition (\%) & Support (\%) & Total (\%) \\
\hline Dominant stakeholders & $15(30.6)$ & $0(0)$ & $34(69.4)$ & $49(100)$ \\
Discretionary stakeholders & $3(42.8)$ & $2(28.6)$ & $2(28.6)$ & $7(100)$ \\
Definitive stakeholders & $116(58.6)$ & $11(5.5)$ & $71(35.9)$ & $198(100)$ \\
Dependent stakeholders & $0(0)$ & $4(30.8)$ & $9(69.2)$ & $13(100)$ \\
Total & $134(50.2)$ & $17(6.4)$ & $116(43.4)$ & $267(100)$ \\
\hline
\end{tabular}

stakeholders were analysed in terms of their attitudes and issues of concern. Table 7 shows the results of an analysis of the attitudes of these four types of powerattributed stakeholders. The table shows that most of the dormant and dangerous stakeholders were opposed to the construction. In contrast, most of the dominant stakeholders supported the policy. Most of the definitive stakeholders held a neutral attitude towards the policy. It is apparent that differences in attitude existed among the different types of power-attributed stakeholders. Table 8 shows the results of an analysis of the issues of concern to these four types of power-attributed stakeholders. The table shows that the biggest issue of concern for dangerous and dormant stakeholders was environmental protection. In contrast, dominant and definitive stakeholders were more concerned with the decision-making process. It is thus apparent that differences existed among the power-attributed stakeholders with respect to the issues of most concern.

\section{Stakeholder types with legitimacy attribute}

Four types of stakeholders (dominant, definitive, discretionary and dependent) possess the attribute of legitimacy. These four types of stakeholders were analysed in terms of their attitudes and issues of concern. Table 9 shows the results of an analysis of the attitudes of these four types of legitimacy-attributed stakeholders. The table shows that most of the discre-tionary and definitive stakeholders had a neutral attitude towards the construction, whereas the attitude held by most of the dominant and dependent stake-holders was supportive. It is apparent that differences in attitude existed among the different types of legitimacy-attributed stakeholders. Table 10 shows the result of an analysis of the issues of concern to these four types of legitimacy-attributed stakeholders. The table shows that differences existed among the issues of concern to the different legitimacyattributed stakeholders. For example, the discretionary stakeholders and the definitive stake-holders showed more concern for environmental issues than did the other two types of stakeholders.

\section{Stakeholder types with urgency attribute}

Four types of stakeholders (dangerous, definitive, dependent and demanding) possess the attribute of 
Table 10. Issues of concern for stakeholder types with legitimacy attribute.

\begin{tabular}{lccccc}
\hline Types of stakeholder & $\begin{array}{c}\text { Environmental } \\
\text { protection (\%) }\end{array}$ & $\begin{array}{c}\text { Transportation } \\
\text { development (\%) }\end{array}$ & $\begin{array}{c}\text { Decision-making } \\
\text { process (\%) }\end{array}$ & $\begin{array}{c}\text { Economic } \\
\text { development (\%) }\end{array}$ & Total (\%) \\
\hline Dominant stakeholders & $4(6)$ & $15(26.8)$ & $30(51.7)$ & $9(15.5)$ & $58(100)$ \\
Discretionary stakeholders & $3(30)$ & $2(20)$ & $3(30)$ & $2(20)$ & $10(100)$ \\
Definitive stakeholders & $51(23.5)$ & $48(22.1)$ & $105(48.4)$ & $13(6)$ & $217(100)$ \\
Dependent stakeholders & $1(5.9)$ & $6(35.3)$ & $2(11.8)$ & $8(47)$ & $17(100)$ \\
Total & $59(19.5)$ & $71(23.5)$ & $140(46.4)$ & $32(10.6)$ & $302(100)$ \\
\hline
\end{tabular}

Table 11. Attitudes of stakeholder types with urgency attribute.

\begin{tabular}{lcccc}
\hline Types of stakeholder & Neutrality (\%) & Opposition (\%) & Support (\%) & Total (\%) \\
\hline Dangerous stakeholders & $21(38.9)$ & $33(61.1)$ & $0(0)$ & $54(100)$ \\
Definitive stakeholders & $116(58.6)$ & $11(5.5)$ & $71(35.9)$ & $198(100)$ \\
Dependent stakeholders & $0(0)$ & $4(30.8)$ & $9(69.2)$ & $13(100)$ \\
Demanding stakeholders & $2(66.7)$ & $0(0)$ & $1(33.3)$ & $3(100)$ \\
Total & $139(51.9)$ & $48(17.9)$ & $81(30.2)$ & $268(100)$ \\
\hline
\end{tabular}

Table 12. Issues of concern to stakeholder types with urgency attribute.

\begin{tabular}{lccccc}
\hline Types of stakeholder & $\begin{array}{c}\text { Environmental } \\
\text { protection (\%) }\end{array}$ & $\begin{array}{c}\text { Transportation } \\
\text { development (\%) }\end{array}$ & $\begin{array}{c}\text { Decision-making } \\
\text { process (\%) }\end{array}$ & $\begin{array}{c}\text { Economic } \\
\text { development (\%) }\end{array}$ & Total (\%) \\
\hline Dangerous stakeholders & $41(70.7)$ & $2(3.4)$ & $7(12.1)$ & $8(13.8)$ & $58(100)$ \\
Definitive stakeholders & $51(23.5)$ & $48(22.1)$ & $105(48.4)$ & $13(6)$ & $217(100)$ \\
Dependent stakeholders & $1(5.9)$ & $6(35.3)$ & $2(11.8)$ & $8(47)$ & $17(100)$ \\
Demanding stakeholders & $0(0)$ & $0(0)$ & $3(100)$ & $0(0)$ & $3(100)$ \\
Total & $93(31.5)$ & $56(19)$ & $117(39.7)$ & $29(9.8)$ & $295(100)$ \\
\hline
\end{tabular}

urgency. These four types of stakeholders were analysed in terms of their attitudes and issues of concern. Table 11 shows the results of an analysis of the attitudes of these four types of urgency-attributed stakeholders. The table reveals differences among the attitudes of the urgencyattributed stakeholders towards the construction. In particular, although most of the definitive and demanding stakeholders had a similar range of attitudes to the project (with the majority being neutral and about a third in support), the dangerous stakeholders demon-strated no support at all for the construction project. In contrast, the majority of the dependent stakeholders supported the construction. Table 12 shows the results of an analysis of the issues of concern to these four types of urgencyattributed stakeholders. It is apparent that the only concern of the demanding stakeholders was the decision making process, whereas most of the dangerous stakeholders were concerned about the issue of environmental protection. The largest proportions of the dependent stakeholders were concerned about economic development, and the largest proportions of the definitive stakeholders were concerned about the decision-making process.
Analyses of salience

\section{Different types of latent stakeholders (only one} attribute)

As noted above, the salience of stakeholders is established on the basis of the number of attributes each stakeholder possesses. Stakeholders possessing any one of the stakeholder attributes fall into the category of latent stakeholders (which include discretionary, demanding and dormant stakeholders). Table 13 shows the attitudes of latent stakeholders towards the highway construction project. The table shows that opposition to the project was much more marked among dormant stakeholders than the other two types; indeed, demanding stakeholders had no opposition to the project at all. Table 14 shows the results of an analysis of the issues of concern to latent stakeholders. The main issue of concern for the discretionary and dormant stakeholders was environmental protection; in contrast, demanding stakeholders were concerned only with the decisionmaking process. 
Table 13. Analysis of attitudes of latent stakeholders.

\begin{tabular}{lcccc}
\hline Types of stakeholder & Neutrality (\%) & Opposition (\%) & Support (\%) & Total (\%) \\
\hline Discretionary stakeholders & $3(42.8)$ & $2(28.6)$ & $2(28.6)$ & $7(100)$ \\
Demanding stakeholders & $2(66.7)$ & $0(0)$ & $1(33.3)$ & $3(100)$ \\
Dormant stakeholders & $10(26.3)$ & $28(73.7)$ & $0(0)$ & $38(100)$ \\
Total & $15(31.2)$ & $30(62.5)$ & $3(6.3)$ & $48(100)$ \\
\hline
\end{tabular}

Table 14. Analysis of issues of concern to latent stakeholders.

\begin{tabular}{lccccc}
\hline Latent stakeholders & $\begin{array}{c}\text { Environmental } \\
\text { protection (\%) }\end{array}$ & $\begin{array}{c}\text { Transportation } \\
\text { development (\%) }\end{array}$ & $\begin{array}{c}\text { Decision-making } \\
\text { process (\%) }\end{array}$ & $\begin{array}{c}\text { Economic } \\
\text { development (\%) }\end{array}$ & Total (\%) \\
\hline Discretionary stakeholders & $3(30)$ & $2(20)$ & $3(30)$ & $2(20)$ & $10(100)$ \\
Demanding stakeholders & $0(0)$ & $0(0)$ & $3(100)$ & $0(0)$ & $3(100)$ \\
Dormant stakeholders & $26(61.9)$ & $2(4.7)$ & $7(16.7)$ & $7(16.7)$ & $42(100)$ \\
Total & $29(52.7)$ & $4(7.3)$ & $13(23.6)$ & $9(16.4)$ & $55(100)$ \\
\hline
\end{tabular}

Table 15. Analysis of attitudes of expectant stakeholders.

\begin{tabular}{lcccc}
\hline Expectant stakeholders & Neutrality (\%) & Opposition (\%) & Support (\%) & Total (\%) \\
\hline Dominant stakeholders & $15(30.6)$ & $0(0)$ & $34(69.4)$ & $49(100)$ \\
Dangerous stakeholders & $21(38.9)$ & $33(61.1)$ & $0(0)$ & $54(100)$ \\
Dependent stakeholders & $0(0)$ & $4(30.8)$ & $9(69.2)$ & $13(100)$ \\
Total & $36(31)$ & $37(31.9)$ & $43(37.1)$ & $116(100)$ \\
\hline
\end{tabular}

Table 16. Analysis of issues of concern to expectant stakeholders.

\begin{tabular}{lccccc}
\hline Expectant stakeholders & $\begin{array}{c}\text { Environmental } \\
\text { protection (\%) }\end{array}$ & $\begin{array}{c}\text { Transportation } \\
\text { development (\%) }\end{array}$ & $\begin{array}{c}\text { Decision-making } \\
\text { process (\%) }\end{array}$ & $\begin{array}{c}\text { Economic } \\
\text { development (\%) }\end{array}$ & Total (\%) \\
\hline Dominant stakeholders & $4(6.9)$ & $15(25.9)$ & $30(51.7)$ & $9(15.5)$ & $58(100)$ \\
Dangerous stakeholders & $41(70.7)$ & $2(3.4)$ & $7(12.1)$ & $8(13.8)$ & $58(100)$ \\
Dependent stakeholders & $1(5.9)$ & $6(35.3)$ & $2(11.8)$ & $8(47)$ & $17(100)$ \\
Total & $46(34.6)$ & $23(17.3)$ & $39(29.3)$ & $25(18.8)$ & $133(100)$ \\
\hline
\end{tabular}

\section{Different types of expectant stakeholders (two attributes)}

As previously noted, stakeholders with any two of the attributes fall within the category of expectant stakeholders (which include dominant, dependent and dangerous stakeholders). Table 15 shows the results of an analysis of the attitudes of expectant stakeholders with regard to the highway construction project. It is apparent that the majority of both the dominant stakeholders and the dependent stakeholders supported the construction project, whereas most of the dangerous stakeholders were opposed. Table 16 shows the results of an analysis of the issues of concern to expectant stakeholders. The results indicate that an overwhelming majority of the dangerous stakeholders were concerned about environmental protection issues. In contrast, dominant and dependent stakeholders paid little attention to this issue; they more concerned about the decision-making process and economic development, respectively.

\section{DISCUSSION}

\section{General findings}

The public policy analytical model established in the study can detect up to 14 points of conflict in the competing demands of various stakeholders (Tables 3 to 16). Five levels of conflict can thus be defined: (i) high conflict (in which the overall number of points of conflict 
is 12 to 14); (ii) medium-to-high conflict (9 to 11 points of conflict); (iii) medium conflict (6 to 8); (iv) medium-to-low conflict (3 to 5); and (v) low conflict (2 or fewer points of conflict). In the empirical case study described above, the data analysis indicated that 12 points of conflict existed among the stakeholders in the construction project under examination. Of the 12 points of conflict, two were identified in the stakeholder salience analysis (Tables 5 and 6), which found different attitudes and issues of concern among the stakeholders of different salience. For example, due to concern about environmental issues, most of the latent stakeholders (those with only one of the stakeholder attributes) were opposed to the project. In the analysis of stakeholder type, a further six points of conflict were found to exist among the attitudes and issues of concern of the stakeholders of different attributes (Tables 7 to 12). Finally, four points of conflict were found among the attitudes and issues of concern of stakeholders of different salience (Tables 13 to 16). The construction project studied here can thus be classified as a 'highconflict' public policy. This result is consistent with the fact that the planning and execution of Taiwan's No. 5 National Highway construction project has been associated with conflicts and controversy among stakeholders for a long time (since 2003). The results of the present study and the obvious tension that exists among the project's stakeholders (as covered by the mass media) indicate that it is necessary for the relevant authorities to identify ways to resolve the conflicts within a short period of time.

\section{Findings with regard to types of stakeholders}

Chang et al. (2010) suggested that before public policy can be developed, it is necessary for the management team to identify the key stakeholders, understand their complex relationships, and focus appropriate resources on them.

\section{Definitive stakeholders}

Given that definitive stakeholders can have an immediate effect on an organisation because they possess all three of the stakeholder attributes (Mitchell et al., 1997), the demands of the definitive stakeholders in this case study should receive close attention. These stakeholders (such as central government agencies and directors of the central ministries) have the power, legitimacy and urgency to formulate and execute decisive public policy with regard to this project. The demands of the definitive stakeholders in this case should therefore be accorded the highest priority and consideration. In particular, the definitive stakeholders in this project have indicated their concern with the decision-making process. They argue that it needs to conduct with a high level of communication with a view of achieving a common understanding between the central government and the various local governments, which often have different interests and opinions. In the interests of promoting the common good for the general public, the definitive stakeholders contend that disagree-ment among the various parties must be minimised and an agreed consensus reached.

\section{Expectant stakeholders}

Expectant stakeholders (those with two of the three stakeholder attributes) can become definitive stakeholders if they obtain the third attribute (Mitchell et al., 1997). The concerns of this type of stakeholder must therefore be considered carefully. The expectant stakeholders in this case include: (i) 'dangerous' stakeholders (such as environmental protection activist groups); (ii) 'dependent' stakeholders (such as local tourism associations and syndicates); and (iii) 'dominant' stakeholders (such as local government agencies). The dangerous stakeholders, such as environmental activists, do not possess direct influence over decisions regarding the construction project, but they are nevertheless 'dangerous' stakeholders because they can convey the urgency of their ecological demands to those who do make the decisions by means of protest activities and public-relations campaigns involving the general public.

The dependent stakeholders, such as local tourism associations, possess the attributes of legitimacy and urgency, but they also have no direct power over decisions on the construction project. Nevertheless, their views are significant because they have large financial resources and a significant influence on the region's economic development; as such, their opinion that the construction of the national highway will be good for economic prosperity must be taken into account by decision-makers. Finally, most of the dominant stakeholders such as local government agencies support the construction of the highway to improve traffic flows and enhance the lives of the local citizens. The local governments complain that the decision-making of central government is inconsistent and not conducive to local development. Local government agencies and officials are therefore unanimous that central govern-ment should make its final decisions on the construction of the highway as soon as possible, thus lessening what they perceive as a lack of balance between development in west and east Taiwan.

\section{Latent stakeholders}

Latent stakeholders (those with only one of the stakeholder attributes) do not have any immediate effect 
on the construction organisation. Nonetheless, their demands still need continuous attention. In this case, these include 'dormant' stakeholders (such as scholars), 'discretionary' stakeholders (such as local citizens), and 'demanding' stakeholders (such as the construction contractors). The dormant stakeholders in this case study were largely represented by academics, who are particularly concerned with the issue of environmental protection; as a consequence, they largely oppose the construction of the No. 5 National Highway. The discretionary stakeholders in this case study were represented by local citizens, who possess the attribute of legitimacy through their democratic voting rights; however, to be effective, this legitimacy needs support from elected representatives in assemblies and parliaments. Some local citizens oppose the construction project on environmental grounds, whereas others support the project because they believe that it will enhance local economic prosperity. The demanding stakeholders in this case study were represented by the construction contractors, who possess the attribute of urgency. After having their tender accepted, they have found that paralysis in decision-making has prevented the deployment of machinery and personnel, which has meant that they have suffered significant (ongoing) financial losses. These stakeholders are therefore very urgent about the construction, but lacking in legitimacy. They cannot begin construction until central government gives them permission to proceed. They are therefore concerned about the decision-making process, and wish to see the government make a definitive decision on construction as soon as possible.

\section{CONCLUSIONS AND SUGGESTIONS}

The present study has developed a public policy analytical model consisting of two stages and two layers. The model, which is based on the stakeholder identi-fication and salience typology of Mitchell et al. (1997), has used the number of conflict points among stake-holders to categorise the degree of stakeholder conflict in public policy projects into five levels: (i) high conflict; (ii) medium-to-high conflict; (iii) medium conflict; (iv) mediumto-low conflict; and (v) low conflict. The study has then taken the construction of the No. 5 National Highway in Taiwan as an empirical case to demonstrate the feasibility of the public policy analytical model. The results of the analysis have shown that the No. 5 National Highway construction is a high-conflict public policy that is in urgent need of a suitable solution. The public policy analytical model proposed in this study is potentially helpful in identifying the multiple stakeholders involved in the project and understanding the attitudes and issues of concern to these stakeholders. It is thus a useful tool for government agencies to utilise in this particular project and in the process of establishing other public policies.

Public managers should adopt the order of priority developed in the model by prioritising the satisfaction of the demands of the most influential (definitive) stakeholders.

The satisfaction of expectant stakeholders should be adopted as the second priority by public mangers, while simultaneously noting developments among latent stakeholders. In undertaking this research, it became apparent that poor communication among the central and local governments and other people involved in the issue was quite a significant factor in fostering disagree-ments among the various parties. Misunderstandings and unnecessary disputes often arose from the vagueness, asymmetry and miscommunication of information. It is suggested that coordination meetings and public hearings should be held frequently to reduce the likelihood of miscommunication among stakeholders and improve the administrative efficiency of government agencies. Finally, although the contributions of this paper are clear, the findings of the study must be utilised with caution because only one empirical case study was conducted to demonstrate how the public policy analy-tical model is implemented, there is merit in further explorations being undertaken with regard to similar issues. Further case studies could be conducted on different public policies to improve the practicability of the model developed in this study. This could include in-depth interviews with relevant decision-makers to enhance the feasibility and applicability of the proposed public policy analytical model.

\section{ACKNOWLEDGMENT}

This study was funded by the National Science Council, Republic of China (Taiwan) (NSC 98-2221-E-412-001MY2).

\section{REFERENCES}

Becker LB (1979). Newspaper and television dependencies: Effects on evaluations of public officials. J. Broadcast., 23: 465-475.

Bendheim C, Graves S (1998). Determining best practice in corporate stakeholder relations using date envelopment an industry level study. Bus. Soc., 37: 306-339.

Brenner SN, Cochran P (1991). The stakeholder theory of the firm: implications for business and society theory and research. Paper presented at The Annual Meeting of the International Association for Business and Society, Sundancd. UT.

Brenner SN, Molander EA (1977). Is the ethics of business changing? Harvard Bus. Rev., 58(1): 54-65.

Bryson J (1995). Strategic planning for public and nonprofit organizations. CA: Josscy-Bass. San Francisco.

Bryson J (2004). What to do when stakeholder matter. Public Manage. Rev., 6: 21-45.

Chang LH, Yu CP, Hung CY (2010). Assessing Stakeholders Participants as a Means of E-Govern in Taiwan. J. Inf. Manage., 17(2): 201-231.

Chen CK, Yu CH, Chang HC (2006). ERA model: A customerorientated organizational change model for the public service. Total Qual. Manage. Bus. Excel., 17(10): 1301-1322.

Cooper DR, Schindler PS (2008). Business research methods. New York: McGraw-Hill. 
Cyert RM, March JG (1963). The behavioral theory of the firm. Englewood Cliffs. NJ: Prentice-Hall.

Donaldson T, Preston LE (1995). The stakeholder theory of the corporation: Concepts, evidence, and implications. Acad. Manage. Rev., 20: 65-91.

Ferlie E, Hartley J, Martin S (2003). Changing public service organizations: Current perspectives and future prospects. Brit. J. Manage., 14: 1-14.

Freeman RE (1984). Strategic management: A stakeholder approach. Pitman, Boston.

Gomes R, Liddle J, de Oliveira Miranda Gomes L (2010). CrossCultural Analysis of Stakeholder Identification in Municipal Districts. Pub. Manage. Rev., 12(1): 53-75.

Hill CWL, Jones TM (1992). Shareholder value, stakeholder management, and social issues: What's the bottom line? Strat. Manage. J., 22: 125-139.

Hillman AJ, Keim GD (2001). Board composition and stakeholder performance: Do stakeholder directors make a difference? Bus. Soc., 40(3): 295-314.

Jones TM, Felps W, Bigley GA (2007). Ethical Theory and StakeholderRelated Decision: The Role of Stakeholder Culture. Acad. Manage. Rev., 32(1): 137-155.

Kaplan R, Norton D (1996). The balanced scorecard MA: Harvard Business School Press. Boston.

Legnick-Hall CA (1996). Customer contributions to quality: A different view of the customer-oriented firm. Acad. Manage. Rev., 21: 791824.

Liao WC, Lin YY, Yu PH (2009). Perceived Stakeholder Importance on Organizational Performance: Mediation Effect of Corporate Responsibility Practice. J. Manage., 26(2): 213-232.

McAdam R, Hazlett SA, Casey C (2005). Performance management in the UK public sector: Addressing multiple stakeholder complexity. Int. J. Pub. Sector Manage., 18(3): 256-273.

Mitchell RK, Agle BR, Wood DJ (1997). Toward a theory of stakeholder identification and salience: Defining the principle of who and what really counts. Acad. Manage. Rev., 22(4): 853-886.

Moore M (1995). Creating public value. Cambridge. MA: Harvard University Press.
Nutt $P$ (2002). Why decisions fail: Avoiding the blunders and traps that lead to debacles. CA: Berrett-Koehler Publishers. San Francisco.

Oliver C (1991). Strategic responses to institutional processes. Acad. Manage. Rev., 16: 145-179.

Rainey H (1997). Understanding and managing public organizations. 2nd ed. CA: Jossey-Bass. San Francisco.

Rainmaker XKM International Corp (2006). Paper readership ranking in Taiwan in 2005, from http://www.rainmaker.com.tw/mrd_np.htm.

Rowley TJ (1997). Moving beyond dyadic ties: A network theory of stakeholder influences. Acad. Manage. Rev., 22(4): 887-910.

Thompson JK, Wartick SL, Smith HL (1991). Integrating corporate social performance and stakeholder management: Implications for a research agenda in small business. Res. Corp. Soc. Perform. Pol., 12: $207-230$.

Wang SM, Feng CM, Hsieh CH (2010). Stakeholder perspective on urban transport system service quality. Total Qual. Manage. Bus. Excel., 21(11): 1103-1119.

Weber M (1947). The Theory of social and economic organization. New York: Free Press. 